\title{
Memoria emocionada de Alberto Blecua
}

Alberto Blecua -fallecido en este mismo año de 2020, el 28 de eneroacompañó siempre a Hesperia; antes, incluso, de que fuera una realidad. En aquellos años finales del siglo pasado, cuando me incorporé a la Universidad de Vigo y concebimos - Antonio Rifón bien lo sabe- esta revista que ya cumple veintitrés entregas, fue necesario que nuestro proyecto (un anuario que acogiera trabajos de lengua y literatura españolas en una casi recién nacida Facultad de Filología y Traducción) se viera avalado por unas cuantas personalidades del ámbito en que se inscribía esta publicación periódica.

Le faltó tiempo a Alberto para apoyar este proyecto y él fue una de las firmas que permitieron la existencia de una revista humilde, pero persistente, convencida de su necesidad y pertinencia en un mundo en el que las humanidades dicen menos de los que debieran decir. Desde el primer número, siempre colaborador y dispuesto, Alberto Blecua perteneció al consejo de redacción de Hesperia, Anuario de Filología Hispánica de la Universidad de Vigo que ahora rinde tributo de admiración, de reconocimiento y de gratitud a este maestro de la filología, de quien tanto aprendimos, a quien tanto debemos.

No solo por enseñarnos el sentido, la necesidad y el alcance de la filología; el porqué de leer bien a nuestros clásicos, el porqué de editarlos correctamente: léase sin falta -si no se ha hecho ya- su prólogo a Signos viejos y nuevos (2006) y su Defensa e ilustración de la crítica textual (2009), de donde extraigo estas palabras: "Nosotros, los filólogos — que no desdeñamos los placeres del venusino-, nos hemos sacrificado y lo seguimos haciendo dedicados a las Litterae humaniores para que los textos del pasado se publiquen con la mayor proximidad posible a la palabra de sus autores. Sí, amamos la filología”. También, porque nos hizo llegar todo ese saber sin estridencias, 
sin sarcasmo, sin hosquedad ni prepotencia: lo que importaba no era tanto como se encontraba el uno, con su mala salud de hierro, sino como estaba el otro, el amigo, el colega...

Estudió a los clásicos, aprendimos a leerlos con él; abrió caminos, redescubrió autores y textos - antiguos y modernos-: toda o casi toda la literatura del Siglo de Oro se puede explicar a partir de sus trabajos y ediciones; así lo hice yo en la primavera de este año recordando a Alberto, día tras día, en mi clase de Literatura española del siglo XVII. Pequeño, humilde reconocimiento que, en el fondo - y en la forma- no perseguía otro propósito que mostrar a mis estudiantes el legado que Alberto nos transmitió: conocer lo pasado para entender mejor el presente.

En este año trágico de 2020 en que tantos maestros se nos están yendo, la ausencia ya definitiva de Alberto Blecua constituye un hito especialmente doloroso.

Quienes contribuimos a que Hesperia siga adelante lloramos su ausencia, reconocemos su trayectoria, agradecemos su magisterio y le devolvemos -negro sobre blanco- todo el afectó que nos dispensó.

Descansa en paz, querido Alberto.

José Montero Reguera Director de Hesperia. Anuario de Filología Hispánica 